\title{
EUREKA!: UM ESTUDO SOBRE A VIDA DOS PROFISSIONAIS DA INDÚSTRIA CRIATIVA DE NOVO HAMBURGO/RS
}

\author{
C. M. P. PINHEIRO* e M. BARTH
Universidade Feevale
maxrs@feevale.br* \\ Artigo submetido em dezembro/2014 e aceito em agosto/2016 \\ DOI: $10.15628 /$ holos.2016.2627
}

\section{RESUMO}

A criatividade, em tempos atuais, é um valioso bem do mercado empresarial, pois, é através dela, que profissionais de diversos segmentos podem diferenciarse e gerar valor competitivo em negócios extremamente concorridos. Diante disso, dentro do ambiente criativo, nos últimos anos uma área vem ganhando destaque e notoriedade no cenário nacional: a Indústria Criativa. Sendo assim, o presente trabalho objetiva analisar a vida dos profissionais criativos da cidade de Novo Hamburgo/RS, atendo-se, em um primeiro momento, aos seus dados demográficos e ambientais. Para fins metodológicos, mapeou-se o número total de criativos na cidade (2011) e, através de um cálculo amostral, estabeleceu-se a quantidade final de entrevistados (323). Ao fim da pesquisa, que contou com 339 respondentes, constata-se que o maior número de empregados da Indústria Criativa em Novo Hamburgo é da área publicitária, tem sexo masculino, possui entre 21 e 30 anos, é solteiro, possui ensino superior incompleto, recebe um salário que varia entre $R \$ 724,01$ e $R \$$ $1.448,00$, atua entre $7 \mathrm{~h}$ e $8 \mathrm{~h}$ por dia, não possui uma regra rígida em seu horário, trabalha na sede de uma empresa, acredita que sua remuneração é insuficiente e valoriza fortemente, entre outros itens, o investimento em cursos superiores e/ou livres enquanto fatores de aprimoramento criativo.

PALAVRAS-CHAVE: Indústria Criativa; trabalhadores criativos; Novo Hamburgo/RS.

\section{EUREKA!: A STUDY ABOUT THE LIFE OF PROFESSIONALS OF CREATIVE INDUSTRY OF NOVO HAMBURGO/RS}

\begin{abstract}
Creativity, in modern times, is a valuable asset of the business market, because through it, which professionals from various segments can differentiate and generate competitive value in extremely competitive business. Thus, within the creative environment, an area in recent years has been gaining attention and notoriety on the national scene: Creative Industries. Thus, this study aims to examine the lives of creative professionals from the city of Novo Hamburgo/RS, fidelity to, at first, their demographic and environmental data. For methodological purposes, mapped the total number of creatives in the city (2011) and, through a sample calculation, settled the final number of respondents
\end{abstract}

(323). At the end of the survey, which had 339 respondents, it appears that the largest number of employees of the Creative Industries in Novo Hamburgo is the advertising area, has male has between 21 and 30, is single, has incomplete higher education, receives a salary ranging between $R \$ 724,01$ and $R \$ 1,448.00$, operates between 7 and 8 hours each day, does not have a strict rule in his time, working at the headquarters of a company, believes that their pay is insufficient and values strongly, among other things, investment in higher and/or free while the creative enhancement factors courses. 


\section{INTRODUÇÃO}

A criatividade, em tempos atuais, é um valioso bem do mercado empresarial, pois, é através dela, que profissionais de diversos segmentos podem diferenciar-se e gerar valor competitivo dentro de negócios extremamente concorridos. Para Felício (2014), os trabalhadores da área criativa, além de possuírem uma maior probabilidade de encontrar a satisfação pessoal, são mais bem remunerados e beneficiados pelas atividades que exercem. Diante disso, dentro do ambiente criativo, nos últimos anos, uma área vem ganhando destaque e notoriedade entre aqueles que, aos poucos, vão conhecendo-a e, claro, dos que já estão nela inseridos. Trata-se da Indústria Criativa que, cada vez mais, ganha força no cenário nacional, tanto que, em 2012, o Governo Federal criou a SEC - Secretária de Economia Criativa -, órgão responsável por alavancar e fomentar a área no Brasil.

Sob esse prisma, Reis (2012) disserta que, em cada localidade do País, o conceito ganha força e surgem novas demonstrações do potencial econômico que a Indústria Criativa pode prover. Dessa forma, o presente trabalho objetiva analisar a vida dos criativos da cidade de Novo Hamburgo/RS, atendo-se, em um primeiro momento, aos dados demográficos e ambientais dos trabalhadores da área criativa no local. Para tanto, são utilizados, buscando fundamentar a discussão, conceitos de Howkins (2002), Bendassolli et al. (2009), Deheinzelin (2011), Reis (2012), entre outros.

O artigo está estruturado da seguinte forma: a próxima seção deste trabalho traz à tona as questões relativas à Indústria Criativa, buscando construir uma base sólida para as discussões que serão propostas na análise. A metodologia empregada é destacada na seção seguinte, demonstrando os critérios utilizados pelos pesquisadores para a construção deste trabalho. Na sequência, a próxima seção destaca a análise deste estudo, com elementos referentes à coleta dos dados e, posteriormente, um aprofundamento analítico buscando, sobretudo, compreender o atual cenário criativo na cidade de Novo Hamburgo/RS. Por fim, destacam-se as considerações finais e as referências utilizadas nesta investigação.

\section{INDÚSTRIA CRIATIVA}

No fim dos anos 1990, o Departamento de Cultura, Mídia e Esportes (DCMS) do Reino Unido lançou um mapeamento da Indústria Criativa, cunhando, assim, um novo conceito, demonstrando que determinadas empresas podem ir além de seu papel cultural e podem, de maneiras mercadológicas, gerar valores consideráveis (HOWKINS, 2002).

O termo, de forma sucinta, refere-se a uma indústria onde o trabalho criativo é preponderante e onde o resultado alcançado é a propriedade intelectual (BENDASSOLLI et al., 2009). Deheinzelin (2011) define a Indústria Criativa como uma economia baseada em recursos intangíveis, já que sua principal matéria-prima é a ideia. Para a autora, nunca chegaremos, inclusive, a uma real definição da área e estaremos, sempre, em uma "versão Beta". Contudo, não possuir um conceito definitivo e absoluto pode, de alguma forma, ser benéfico pois, neste caso, cada local adequa-se à significação que mais Ihe convém (REIS, 2012). 
Embora os conceitos tenham inúmeras redações, há um elemento central em destaque: a criatividade; é através dela que, conforme Simonton (2000), novos negócios surgem e a economia pode avançar em sentidos exponenciais. Para Nicolaci-da-Costa (2011), a criatividade é o componente-chave para a difusão dos negócios do futuro, atraindo olhares dos mais diversos campos.

Assim como, ainda, não há uma definição clara do conceito, há, também, imprecisões nas áreas que compõem a Indústria Criativa (REIS, 2012). O quadro a seguir demonstra os modelos comumente usados, como o Modelo do DCMS, o Modelo de Textos Simbólicos, o Modelo de Círculos Concêntricos e o Modelo de Direitos Autorais.

Quadro 1 - Sistemas de classificação para as indústrias criativas derivados dos diferentes modelos internacionais

\begin{tabular}{|c|c|c|c|}
\hline $\begin{array}{c}\text { MODELO DO DEPARTAMENTO } \\
\text { DE CULTURA, MÍDIA E ESPORTE } \\
\text { DO REINO UNIDO }\end{array}$ & $\begin{array}{l}\text { MODELO DE TEXTOS } \\
\text { SIMBÓLICOS }\end{array}$ & $\begin{array}{l}\text { MODELO DE CíRCULOS } \\
\text { CONCÊNTRICOS }\end{array}$ & $\begin{array}{c}\text { MODELO DE DIREITOS } \\
\text { AUTORAIS }\end{array}$ \\
\hline \multirow{4}{*}{$\begin{array}{l}\text { Publicidade } \\
\text { Arquitetura } \\
\text { Mercado de arte e } \\
\text { antiguidades } \\
\text { Artesanato } \\
\text { Design } \\
\text { Moda } \\
\text { Filme e vídeo } \\
\text { Música } \\
\text { Artes cênicas } \\
\text { Publicação } \\
\text { Software } \\
\text { Televisão e rádio } \\
\text { Videogames e jogos para } \\
\text { computador }\end{array}$} & $\begin{array}{l}\text { Núcleo das indústrias } \\
\text { culturais } \\
\text { Publicidade } \\
\text { Filme } \\
\text { Internet } \\
\text { Música } \\
\text { Publicação } \\
\text { Televisão e rádio } \\
\text { Videogames e jogos para } \\
\text { computador }\end{array}$ & $\begin{array}{l}\text { Núcleo das artes criativas } \\
\text { Literatura } \\
\text { Música } \\
\text { Artes cênicas } \\
\text { Artes visuais }\end{array}$ & $\begin{array}{l}\text { Núcleo das indústrias de } \\
\text { direitos autorais } \\
\text { Publicidade } \\
\text { Associações de } \\
\text { colecionadores } \\
\text { Filme e vídeo } \\
\text { Música } \\
\text { Artes cênicas } \\
\text { Publicação } \\
\text { Software } \\
\text { Televisão e rádio } \\
\text { Arte gráfica e visual }\end{array}$ \\
\hline & $\begin{array}{l}\text { Indústrias culturais } \\
\text { periféricas } \\
\text { Artes criativas }\end{array}$ & $\begin{array}{l}\text { Outros núcleos das } \\
\text { indústrias culturais } \\
\text { Filme } \\
\text { Museus e bibliotecas }\end{array}$ & $\begin{array}{l}\text { Indústrias de direitos } \\
\text { autorais interdependentes } \\
\text { Material de gravação em } \\
\text { branco } \\
\text { Eletrônicos de consumo } \\
\text { Instrumentos musicais } \\
\text { Papel } \\
\text { Fotocopiadoras, } \\
\text { equipamento fotográfico }\end{array}$ \\
\hline & \multirow[t]{2}{*}{$\begin{array}{l}\text { Indústrias culturais de } \\
\text { fronteira } \\
\text { Eletrônicos de consumo } \\
\text { Moda } \\
\text { Software } \\
\text { Esporte }\end{array}$} & $\begin{array}{l}\text { Indústrias culturais mais } \\
\text { amplas } \\
\text { Serviços de preservação da } \\
\text { herança cultural } \\
\text { Publicação } \\
\text { Gravação de som } \\
\text { Televisão e rádio } \\
\text { Videogames e jogos para } \\
\text { computador }\end{array}$ & \multirow[t]{2}{*}{$\begin{array}{l}\text { Indústrias de direitos } \\
\text { autorais parciais } \\
\text { Arquitetura } \\
\text { Vestuário, calçados } \\
\text { Design } \\
\text { Moda } \\
\text { Artigos domésticos } \\
\text { Brinquedos }\end{array}$} \\
\hline & & $\begin{array}{l}\text { Indústrias relacionadas } \\
\text { Publicidade } \\
\text { Arquitetura } \\
\text { Design } \\
\text { Moda }\end{array}$ & \\
\hline
\end{tabular}

Fonte: Valiati $(2013$, p. 11)

Percebe-se, através do quadro exposto, que há áreas que se repetem nos diferentes modelos, como, por exemplo, Publicidade, Música e Filmes. Contudo, há segmentos exclusivos de 
determinados sistemas, como o Esporte, localizado, apenas, no Modelo de Textos Simbólicos. Isso ocorre pela diferença cultural nas diversas dimensões que ela afeta, como sociedade e governo; ou, ainda, pelas especificidades e potenciais mercadológicos de determinadas regiões, fazendo com que os conceitos flexibilizem a necessidade de um norteamento filosófico nacional.

O fato é que, embora sua prática já exista há algum tempo, o debate em torno da Indústria Criativa é, relativamente, recente. Sendo assim, conforme Chapain e Comunian (2011), não cabe pelo menos nesses primeiros momentos - uma discussão acirrada buscando consolidar um modelo definitivo; basta, apenas, deixar que o tempo se encarregue de estabelecer uma definição mais concreta.

A seção seguinte objetiva demonstrar os métodos utilizados neste trabalho.

\section{PROCEDIMENTOS METODOLÓGICOS}

A presente seção tem por objetivo apresentar o percurso metodológico a ser trilhado para a realização desta pesquisa. Inicialmente, o estudo buscou levantar informações referentes à quantidade de criativos presentes em cada um dos segmentos que compõem a Indústria Criativa em Novo Hamburgo/RS. Para isso, utilizou-se, como base, um estudo realizado pela FIRJAN Federação das Indústrias do Rio de Janeiro, o qual mapeou diversas cidades do País, buscando definir o cenário criativo das mesmas. Ao acessar o site disponibilizado pela Instituição, é possível filtrar a busca selecionando itens como ano ${ }^{1}$, estado, município e segmento. A seguir, demonstram-se os resultados da busca realizada.

\begin{tabular}{|c|c|}
\hline Segmentos & Números \\
\hline Arquitetura \& Engenharia & 142 \\
\hline Artes & 58 \\
\hline Artes Cênicas & 11 \\
\hline Biotecnologia & 22 \\
\hline Design & 454 \\
\hline Expressões Culturais & 52 \\
\hline Filme \& Vídeo & 45 \\
\hline Mercado Editorial & 220 \\
\hline Moda & 360 \\
\hline Música & 13 \\
\hline Pesquisa \& Desenvolvimento & 49 \\
\hline Publicidade & 170 \\
\hline Software, Computação \& Telecom & 369 \\
\hline Televisão \& Rádio & 46 \\
\hline Total & 2011 \\
\hline
\end{tabular}

Fonte: Elaborado pelos autores, com base em FIRJAN (2011)

Após estabelecer o valor total (2011 criativos), realizou-se um cálculo amostral para saber quantos trabalhadores da Indústria Criativa de Novo Hamburgo deveriam participar da pesquisa.

\footnotetext{
${ }^{1}$ Os anos disponibilizados para consulta no site da FIRJAN são 2010 e 2011 . Optou-se, nesta pesquisa, pelo ano de 2011.
} 
Com uma margem de $5 \%$ de erro, o valor demonstrado pelo cálculo foi de 323 criativos a serem questionados. Concomitantemente a este processo, elaborou-se um questionário, o qual contemplava questões que serão discutidas posteriormente na análise. Contudo, antes da aplicação efetiva, realizou-se um pré-teste ${ }^{2}$ com 5 criativos selecionados pelos pesquisadores. Os mesmos foram convidados a responder a pesquisa, que foi enviada via e-mail e, após, em horário e local previamente combinados, apontaram sugestões aos pesquisadores, visando o aprimoramento do estudo.

Quadro 2 - Criativos e seus segmentos dentro da Indústria Criativa

\begin{tabular}{|c|c|c|}
\hline Criativos & Segmento dentro da Indústria Criativa & Profissão \\
\hline 1 & Mercado Editorial & Jornalista \\
\hline 2 & Moda & Personal Stylist \\
\hline 3 & Artes & Artista Plástica \\
\hline 4 & Publicidade & Diretor de Arte \\
\hline 5 & Design & Webdesigner \\
\hline
\end{tabular}

Nota: optou-se por manter os nomes dos criativos que contribuíram com o pré-teste em sigilo Fonte: Elaborado pelos autores

Posteriormente, o questionário (apêndice A) foi, de maneira oficial, postado no perfil dos pesquisadores na rede social Facebook ${ }^{3}$, buscando coletar a amostra desejada (323 criativos). Após o post inicial, que foi realizado no dia 15 de maio de 2014, estabeleceu-se que a pesquisa estaria disponível online durante 30 dias. Ao fim do período, os números demonstravam que 339 pessoas haviam respondido. Em seguida, iniciou-se a tabulação dos dados, as quais geraram os resultados que serão discutidos na seção adiante.

\section{RESULTADOS E ANÁLISE}

\subsection{OBJETO DO ESTUDO DE CASO: NOVO HAMBURGO/RS}

O município de Novo Hamburgo, fundado em 5 de abril de 1927, localiza-se a $47 \mathrm{~km}$ de Porto Alegre/RS. Possui, atualmente, 239.051 habitantes, com um PIB geral de R\$ 4.499.416 e um PIB per capita de $\mathrm{R} \$ 17.456,78$. O cenário econômico do município divide-se entre indústrias, comércio e prestação de serviços, com, no momento, 3.029 indústrias, 8.897 comércios e 13.945 serviços ${ }^{4}$.

A cidade é conhecida como "A capital nacional do calçado", pois, devido à significativa produção de sapatos, tornou-se referência neste segmento (SCHEMES et al., 2005). Destaca-se, também, por possuir um clube de futebol - o Esporte Clube Novo Hamburgo - disputando a Série A do Campeonato Gaúcho. Inclusive, no ano de 2014, o clube cedeu seu estádio ao Sport Club Internacional para que o mesmo disputasse suas partidas, enquanto sua arena estava em reformas para a Copa do Mundo do Brasil. Esse fato movimentou o cenário esportivo da região onde a cidade está inserida. O município conta, também, com Instituições de Ensino Superior, destacando-se a

\footnotetext{
2 o pré-teste refere-se ao teste do questionário em uma pequena amostra de entrevistados, com o objetivo de identificar e eliminar problemas potenciais (PRODANOV; FREITAS, 2013).

3 Justifica-se a escolha do Facebook por ser considerada, hoje, a mais representativa rede social do mundo (RYAN; XENOS, 2011; JUNCO, 2013).

${ }^{4}$ Disponível em: <http://www.ibge.gov.br/home/default.php>. Acesso em: 01 mar. 2014.
} 
Universidade Feevale, que oferece inúmeras opções de cursos em todos os níveis de ensino (inclusive, com variados cursos oriundos da Indústria Criativa) ${ }^{5}$.

Figura 1 - Localização de Novo Hamburgo no Rio Grande do Sul

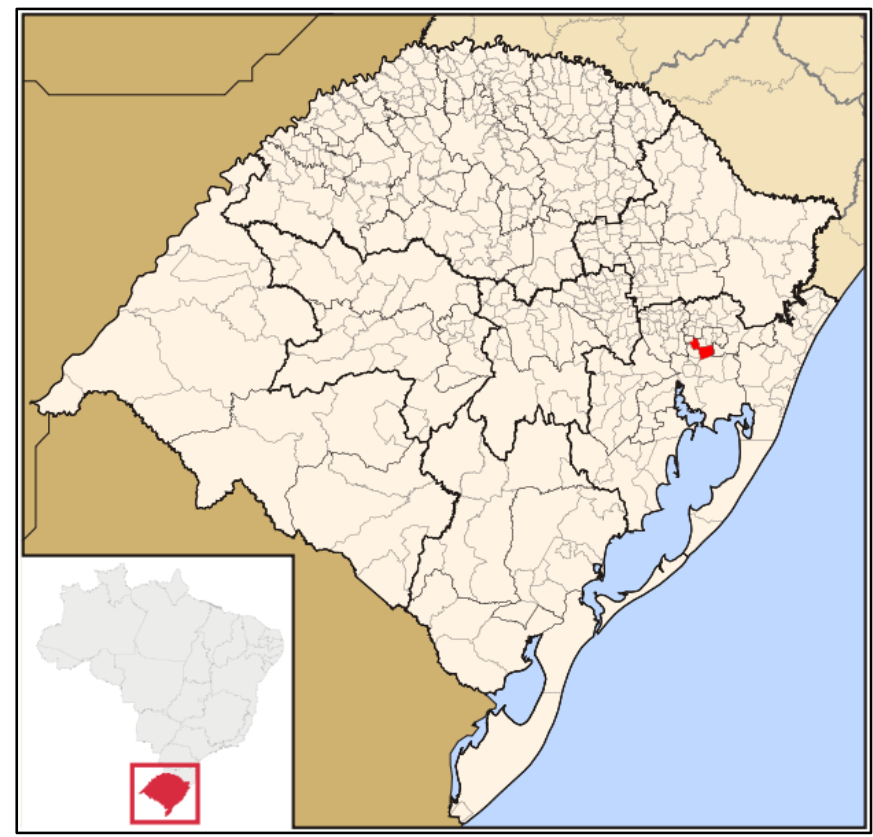

Fonte: Novo Hamburgo (2014, online $)^{6}$

\subsection{DISCUSSÃO DOS RESULTADOS}

Este tópico apresenta a discussão da análise dos resultados, os quais visam demonstrar as constatações dos autores no âmbito desta pesquisa. O questionário dividiu-se em três blocos temáticos que buscavam, de maneira clara, expressar os conceitos e interesses da pesquisa.

Gráfico 1 - Área de formação dentro da Indústria Criativa (em \%)

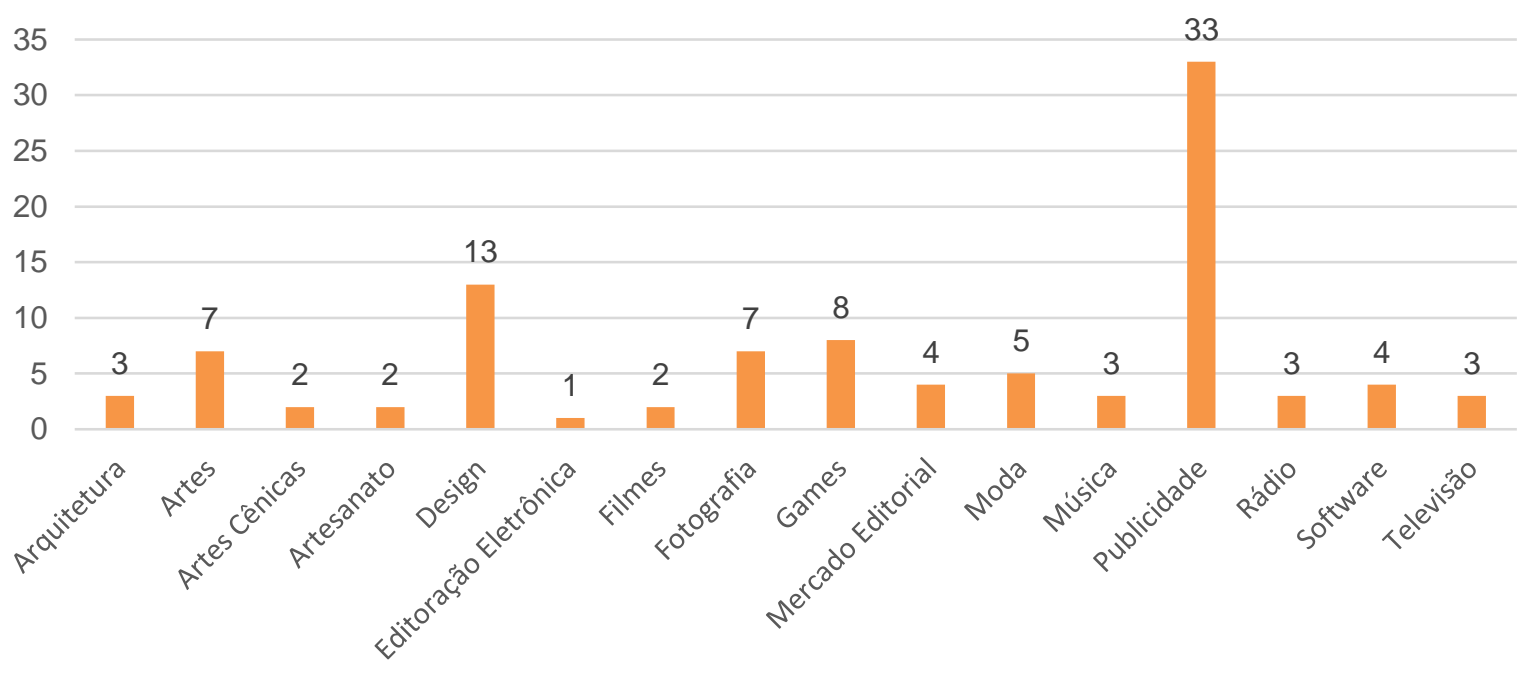

Fonte: Elaborado pelos autores

\footnotetext{
${ }^{5}$ Disponível em: <http://www.feevale.br/ensino>. Acesso em: 01 mar. 2014.

${ }^{6}$ Disponível em: <http://www.novohamburgo.rs.gov.br/>. Acesso em: 01 mar. 2014.
} 
Inicialmente, como uma estratégia que envolvia perguntas-filtro ${ }^{7}$, perguntou-se aos entrevistados a qual área da Indústria Criativa o mesmo pertencia ${ }^{8}$. Conforme apresentam os resultados do gráfico a seguir, o maior número de respondentes é da área publicitária, seguida pelo Design e pelos Games.

O segundo bloco de perguntas dizia respeito aos dados demográficos dos respondentes. Inicialmente, questionou-se o sexo dos entrevistados, sendo que, a maior parte deles (52\%), é do sexo masculino. Tal número, provavelmente, explica-se pelo fato das áreas que demonstraram mais criativos (conforme gráfico anterior) serem, ainda, predominantemente, segmentos masculinizados. Deheinzelin (2011) explica que o setor criativo é, normalmente, constituído por ambos os sexos, contudo, há determinados setores onde certos sexos ainda prevalecem.

\section{Gráfico 2 - Sexo (em \%)}

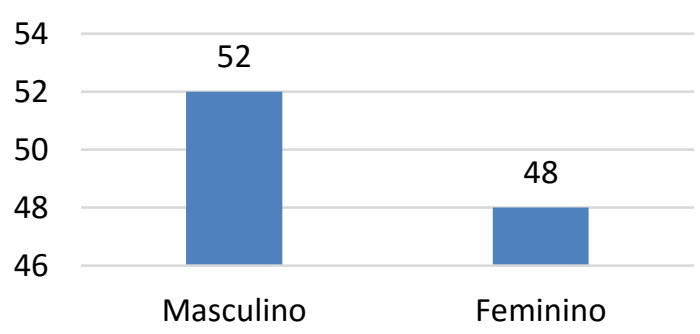

Fonte: Elaborado pelos autores

Na sequência, a pesquisa verificou a idade dos entrevistados, sendo que, como ponto de destaque, acentuou-se a faixa que varia entre 21 e 30 anos. Este intervalo etário é visto por Asheim e Hansen (2009) como um destacado grupo de criativos, pois trata-se de um conjunto composto por universitários em início de carreira, estando, então, em um promissor processo de desenvolvimento profissional. Contudo, é oportuno destacar os respondentes com idade acima de 51 anos, o que, segundo Barth e Musskopf (2012), demonstra uma tendência considerável de idosos nos ambientes criativos, pois os mesmos mantem-se, ainda, em pleno desenvolvimento de suas funções.

Gráfico 3 - Idade (em \%)

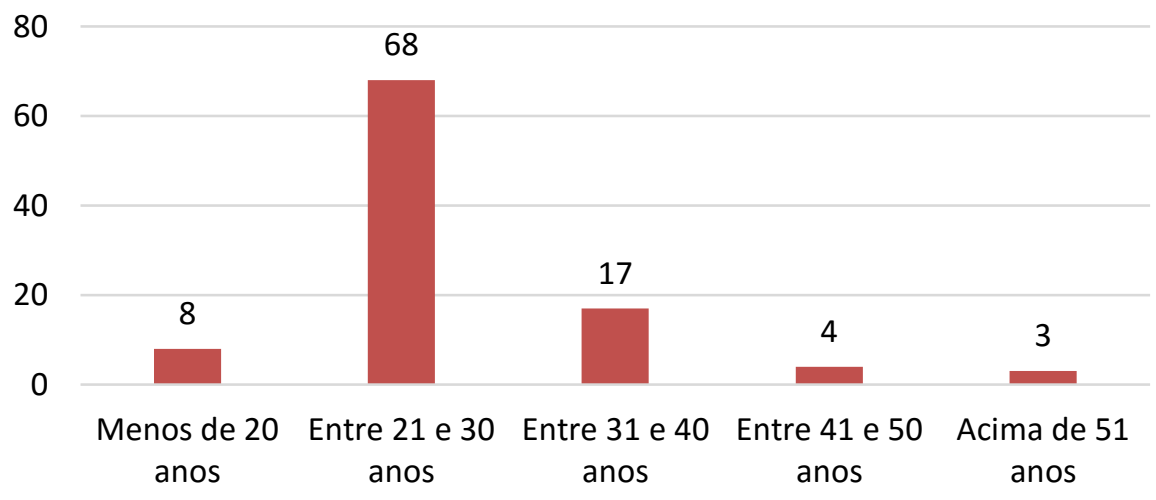

Fonte: Elaborado pelos autores

\footnotetext{
${ }^{7}$ As perguntas-filtro são aquelas feitas previamente a outra pergunta, com a finalidade de eliminar entrevistados que não são afetados por esta (PRODANOV; FREITAS, 2013).

${ }^{8}$ Utilizou-se, para a elaboração do estudo, o modelo proposto pelo Departamento de Cultura, Mídia e Esporte do Reino Unido.
} 
Em seguida, o estudo questionou os entrevistados em relação ao seu estado civil, mostrando que a opção "solteiro" teve o maior número de respostas. As mesmas, possivelmente, explicam-se pelo fato de que, conforme gráfico anterior, a maioria dos respondentes é composta por jovens com menos de 30 anos. Nicolaci-da-Costa (2011) aponta que, atualmente, os jovens brasileiros estão optando por, inicialmente, construir uma sólida carreira profissional antes de constituir laços matrimoniais.

Gráfico 4 - Estado Civil (em \%)

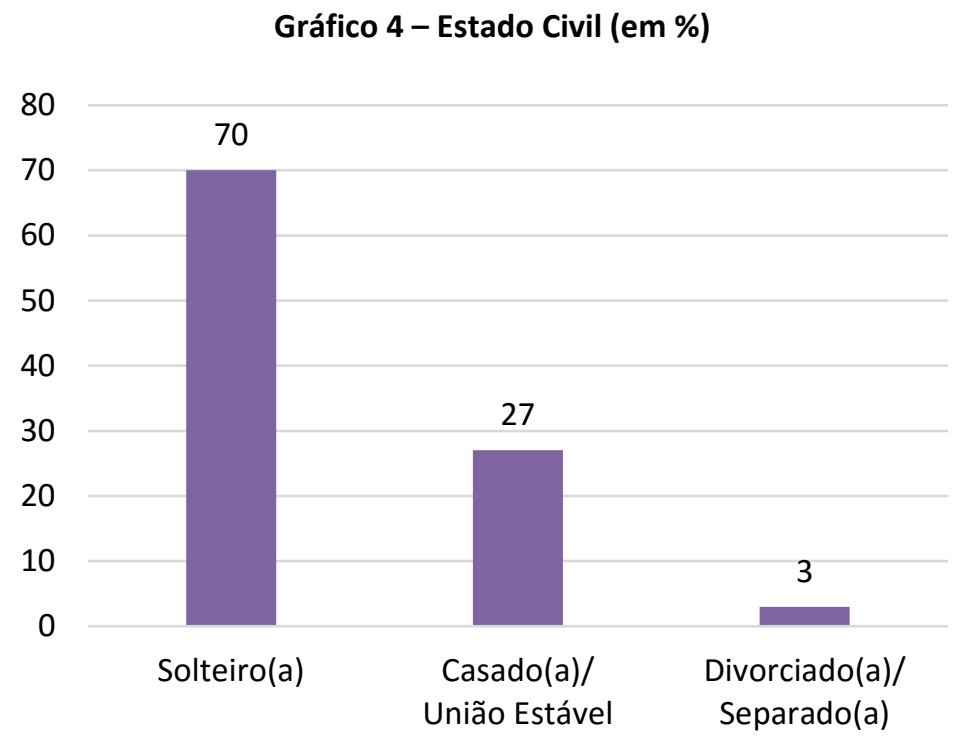

Fonte: Elaborado pelos autores

O estudo buscou, também, dados sobre a formação escolar dos criativos de Novo Hamburgo. Conforme demonstra o gráfico a seguir, há um maior número de estudantes do Ensino Superior no mercado profissional, o que corrobora com os conceitos de Florida (2014). O autor argumenta que é nas universidades que a criatividade movimenta-se e, também, é nas Instituições de Ensino Superior que surgem novos negócios e oportunidades de trabalho.

\section{Gráfico 5 - Formação (em \%)}

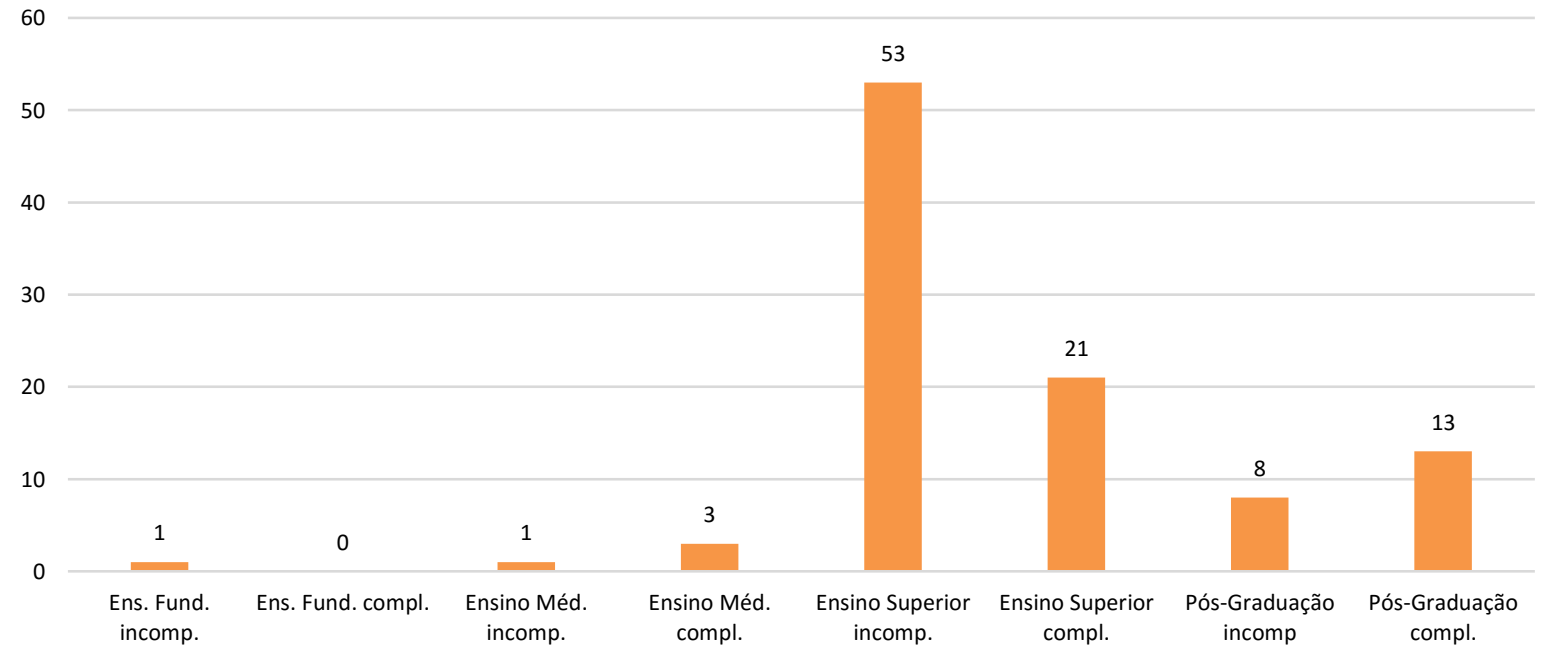

Fonte: Elaborado pelos autores

Conforme mencionado por Felício (2014), os trabalhadores de setores criativos são bem remunerados; pensando nisso, questionou-se os entrevistados em relação a sua faixa salarial. Os 
resultados apontaram que 24 respondentes assinalaram a opção "Até $R \$ 724,00$ ". Imagina-se que, nesta opção de resposta, enquadraram-se os estagiários, já que os salários deste tipo de vínculo são, costumeiramente, mais baixos, partindo da premissa de que os empregados ainda estão em processo de aprendizagem de suas funções. O gráfico a seguir demonstra que a maior parcela dos respondentes ficou na faixa salarial que vai “De $\mathrm{R} \$ 724,01$ até $\mathrm{R} \$ 2.896,00$ ". Dados da Fecomércio apontam que, por exemplo, a remuneração mensal média para o estado do Rio Grande do Sul é de $R \$ 1.600,00^{9}$, estando, portanto, dentro das opções mais respondidas pelos entrevistados.

\section{Gráfico 6 - Faixa salarial mensal (em \%)}

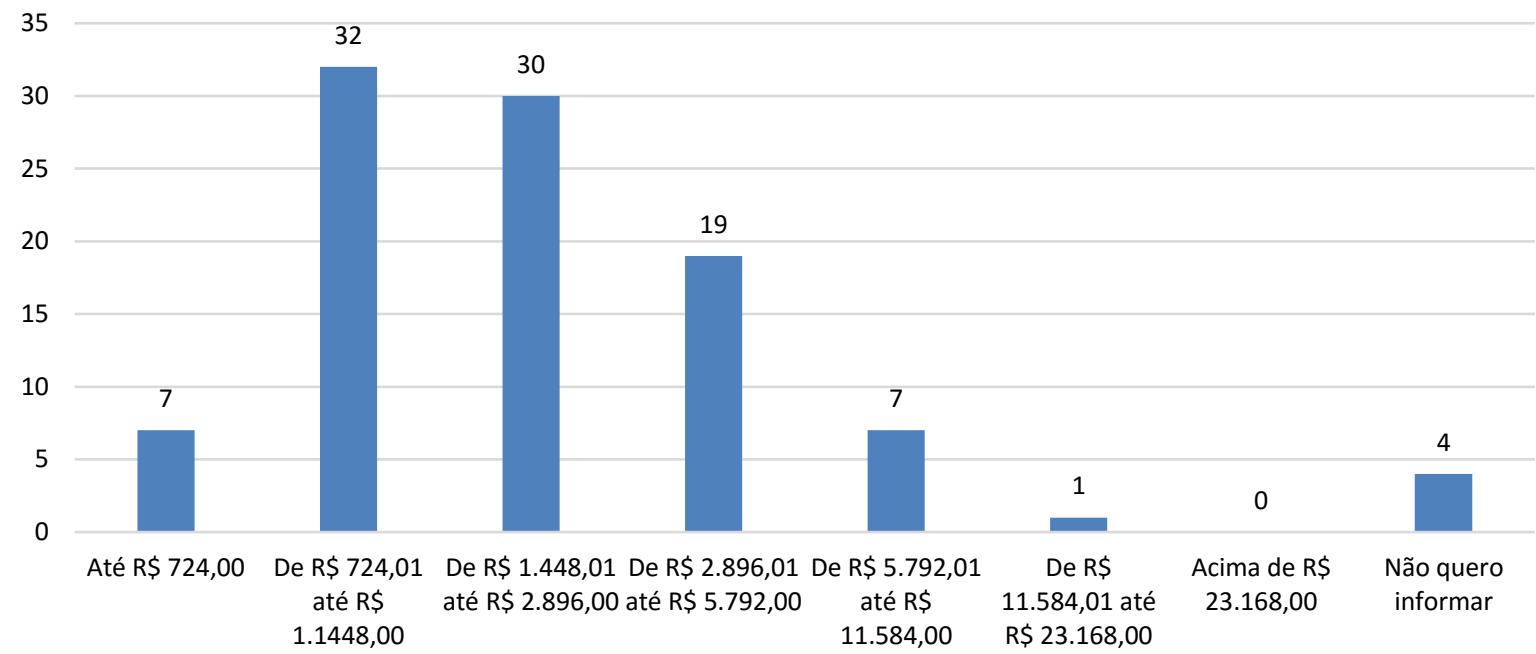

Fonte: Elaborado pelos autores

A pesquisa verificou, também, a carga horária diária dos entrevistados, onde a parcela mais significativa respondeu que se enquadra na opção "Entre 7h e 8h". Para Reis (2012), o tempo diário dedicado às atividades criativas pode variar consideravelmente entre os profissionais do segmento, já que, muitos não possuem uma rotina fixa de trabalho. Entretanto, conforme os dados apontados pela pesquisa, percebe-se que, em Novo Hamburgo, a carga horária diária dos criativos assemelha-se às outras áreas, permanecendo dentro da média nacional, que é de 8 horas diárias ${ }^{10}$.

\section{Gráfico 7 - Carga horária diária (em \%)}

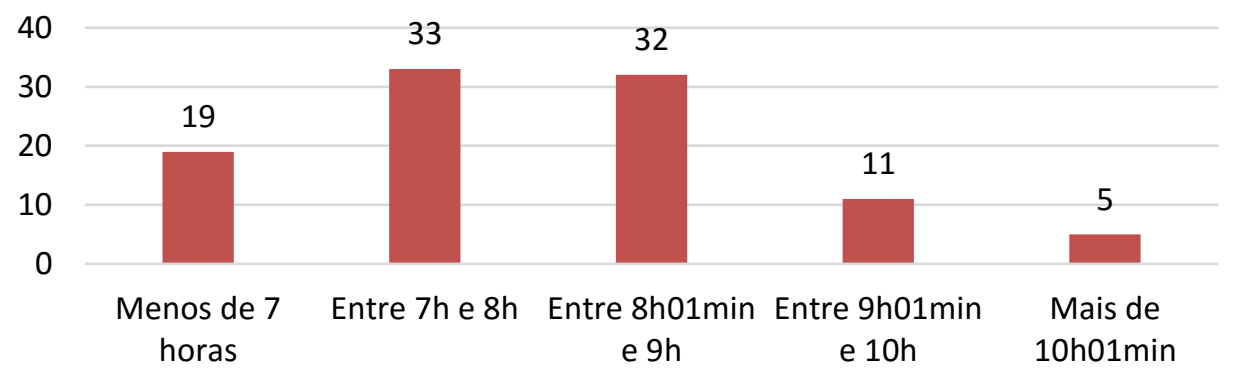

Fonte: Elaborado pelos autores

\footnotetext{
${ }^{9}$ Disponível em: <http://g1.globo.com/rs/rio-grande-do-sul/noticia/2013/01/salario-medio-do-trabalhador-do-rs-foir-16-mil-em-2011-diz-pesquisa.html>. Acesso em: 01 jul. 2014.

10 Disponível em: <http://g1.globo.com/Noticias/Economia_Negocios/0,,MUL1246080-9356,00-CARGA+HORARIA+ DE+TRABALHO+NO+BRASIL+DIMINUI+ENTRE+E+DIZ+IPEA.html>.

Acesso em: 01 mai. 2014.
} 
Examinou-se, através dos dados coletados, que os respondentes de Novo Hamburgo, quando questionados sobre a flexibilidade de sua carga horária diária, responderam, em sua maioria, a opção "Depende, pois não há uma regra rígida. Às vezes chego e saio cedo; às vezes é o contrário". Florida (2014) argumenta que uma das características mais marcantes da área criativa é não possuir um horário rígido; as atividades são realizadas de acordo com a demanda. Como exemplo, é possível citar a área de Artes que não necessita, necessariamente, de um horário de trabalho definido; o artista cria conforme sua inspiração e não limita-se aos horários costumeiramente pré-determinados (BEATO, 2012).

\section{Gráfico 8 - Flexibilidade da carga horária diária (em \%)}

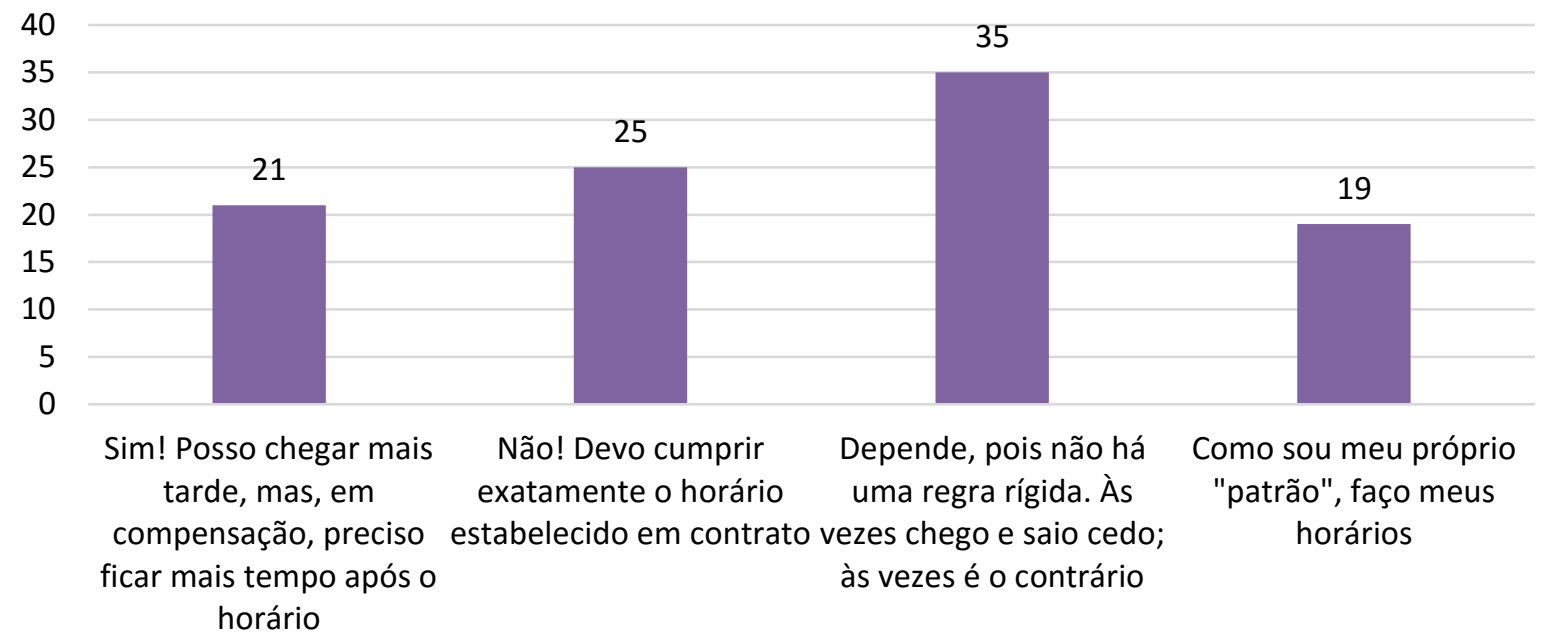

Fonte: Elaborado pelos autores

O Gráfico 9 demonstra o local mais comumente utilizado pelos criativos de Novo Hamburgo para o trabalho. Em uma maioria significativa, a resposta mais assinalada foi "Na sede de uma empresa". Permitiu-se, nesta questão, que os entrevistados assinalassem a opção "Outro" e, também, complementassem a mesma de forma textual. Diante disso, 30 respondentes teceram seus comentários; entre eles, uma resposta fortemente citada foi "albergue de empresas". Ainda, os entrevistados declararam, substancialmente, comentários como "biblioteca", "banco", "laboratório", "universidade" e "escola". Contudo, entende-se que essas respostas enquadram-se na opção "Na sede de uma empresa", não vinculando-se, portanto, à opção "Outro".

Gráfico 9 - Ambiente de trabalho do criativo (em \%)

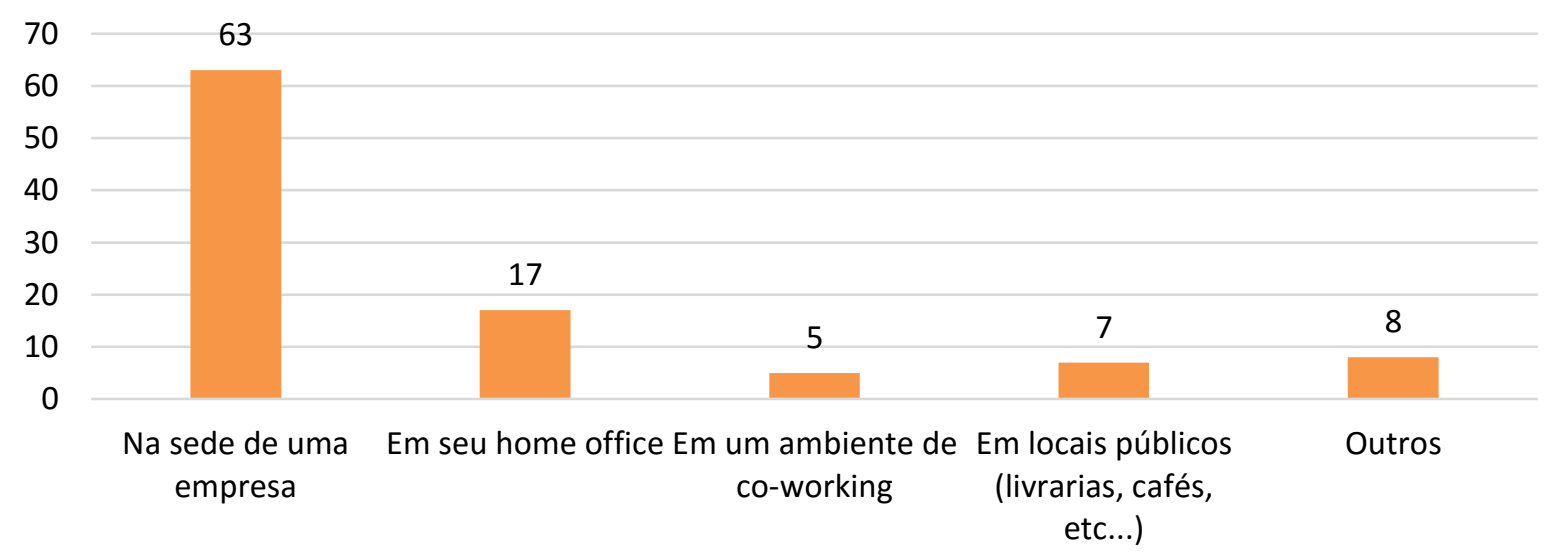

Fonte: Elaborado pelos autores 
Segundo Deheinzelin (2011), os profissionais criativos notabilizam-se por valorizar, além de salários atraentes, os demais benefícios ${ }^{11}$ que a profissão oferece. Dessa forma, o Gráfico 10 retrata a satisfação dos respondentes em relação à remuneração e aos benefícios of erecidos por seus respectivos trabalhos. As opções "Depende! A remuneração não é boa, contudo, os benefícios oferecidos são interessantes" e "Não! Faço um trabalho superior a minha remuneração e os benefícios são insuficientes" foram as que obtiveram maior número de respostas. Nota-se, através das respostas, que há certa insatisfação quanto à remuneração entre os entrevistados, o que, para Bendassolli et al. (2009), é algo relativamente normal nos diversos ambientes profissionais.

Gráfico 10 - Satisfação em relação à remuneração e aos benefícios (em \%)

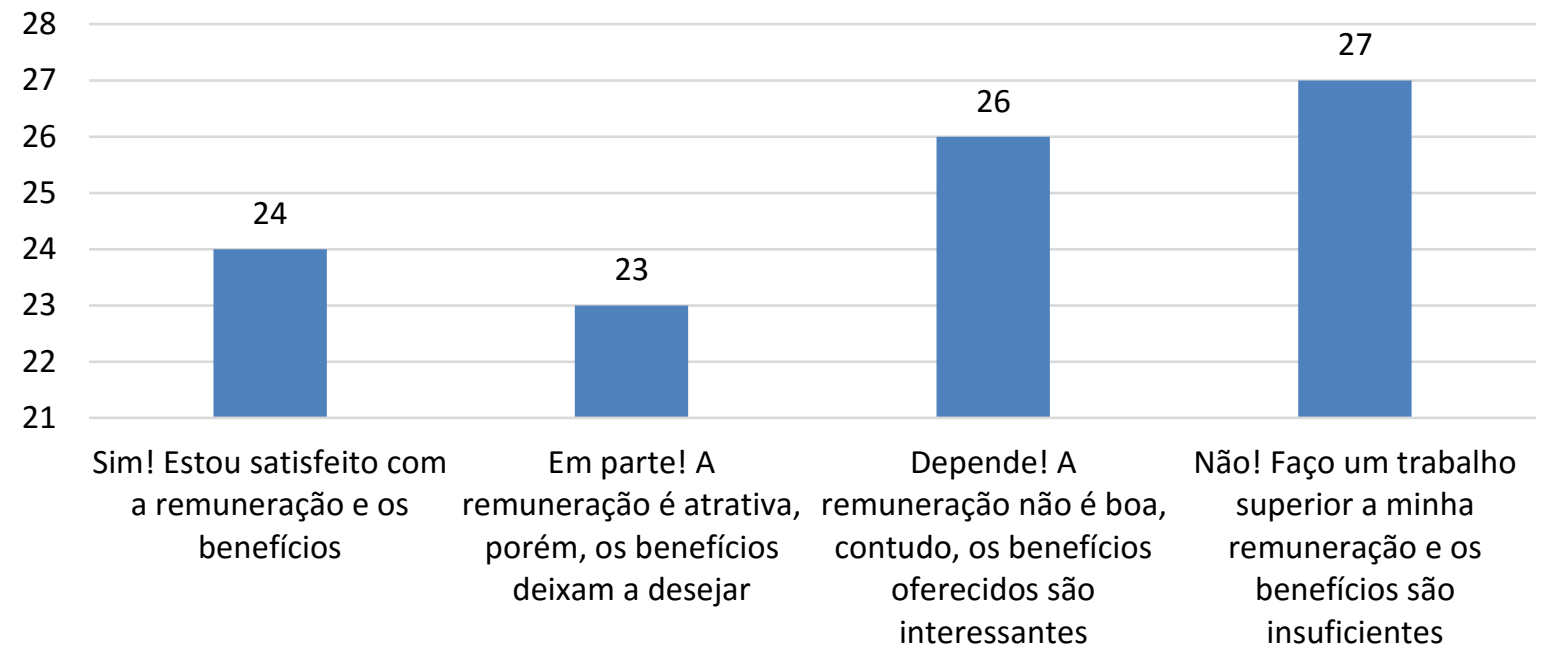

Fonte: Elaborado pelos autores

A Tabela 2, a seguir, explicita os resultados da questão que verificou o grau de importância que os entrevistados dão a determinadas atividades enquanto propulsoras da criatividade. A opção "Investir em cursos superiores e/ou livres" teve destacada importância, resultando em 205 respondentes que veem nesta atividade o grau máximo. "Assistir filmes e séries" demonstrou equilíbrio na opinião dos entrevistados, sendo que, em sua maioria, o grau de importância " 4 " teve um número mais elevado em relação às demais opções. Sobre "Navegar em sites buscando referências", os entrevistados demonstraram forte apelo a esta opção, com os graus " 4 " e " 5 " recebendo boa parte das respostas. Quanto a "Frequentar eventos ligados à área, museus, exposições etc", os respondentes também ratificaram destaque a esta questão, assinalando com evidência os graus " 4 " e " 5 ". 0 item "Praticar esportes e outras atividades que ajudam a desopilar" dividiu as opiniões, não mostrando-se, na visão de alguns entrevistados, significativo, haja visto o número de marcações nos graus "1", " 2 " e " 3 ". Por fim, o item "Curtir o tempo ocioso" demonstrou equilíbrio, com o grau mais baixo de importância apontando 14 respondentes e, o mais alto, 111.

\footnotetext{
${ }^{11}$ Entende-se benefícios como outros aspectos do trabalho que não são, necessariamente, ligados à área financeira, como bom ambiente, desenvolvimento criativo, possibilidade de aprimoramento profissional etc.
} 
Tabela 2 - Pergunta: Dentre as atividades abaixo, qual o grau de importância que você dá a cada uma delas em relação à contribuição das mesmas para seu desenvolvimento enquanto profissional criativo (em \%)

\begin{tabular}{|c|c|c|c|c|c|c|}
\hline & 1 & 2 & 3 & 4 & 5 & $\begin{array}{l}\text { Não } \\
\text { sei/Não se } \\
\text { aplica }\end{array}$ \\
\hline $\begin{array}{l}\text { Investir em cursos superiores } \\
\text { e/ou livres }\end{array}$ & 1 & 2 & 9 & 26 & 61 & 1 \\
\hline Assistir filmes e séries & 1 & 8 & 28 & 41 & 21 & 1 \\
\hline $\begin{array}{l}\text { Navegar em sites buscando } \\
\text { referências }\end{array}$ & 1 & 2 & 10 & 37 & 48 & 2 \\
\hline $\begin{array}{l}\text { Frequentar eventos ligados à } \\
\text { área, museus, exposições etc }\end{array}$ & 1 & 4 & 15 & 35 & 43 & 2 \\
\hline $\begin{array}{l}\text { Praticar esportes e outras } \\
\text { atividades que ajudam a } \\
\text { desopilar }\end{array}$ & 3 & 11 & 31 & 33 & 21 & 1 \\
\hline Curtir o tempo ocioso & 4 & 11 & 21 & 29 & 33 & 2 \\
\hline
\end{tabular}

Nota inserida na questão: entende-se 1 como "pouco importante" e 5 como "importância vital” Fonte: Elaborado pelos autores

Evidenciam-se, na sequência, as considerações finais deste estudo.

\section{CONSIDERAÇÕES FINAIS}

O presente trabalho, atendo-se, em um primeiro momento, a dados demográficos e ambientais, visou analisar a vida dos profissionais criativos da cidade de Novo Hamburgo/RS. Buscou-se, dessa forma, compreender o cenário da Indústria Criativa na cidade, já que, até o momento, não há um documento que possibilite a obtenção de tais dados. A fim de facilitar a compreensão dos resultados da pesquisa, o quadro a seguir estabelece uma síntese dos principais itens ressaltados pelos entrevistados, abordando, sobretudo, as respostas mais sinalizadas pelos respondentes.

Quadro 3-Quadro-síntese com as respostas mais sinalizadas na pesquisa

\begin{tabular}{|l|l|c|}
\hline \multicolumn{1}{|c|}{ Questão } & \multicolumn{1}{|c|}{ Resposta } & Respondentes (em \%) \\
\hline $\begin{array}{l}\text { Área de formação dentro da } \\
\text { Indústria Criativa }\end{array}$ & Publicidade & 53 \\
\hline Sexo predominante & Masculino & 68 \\
\hline Faixa etária & Entre 21 e 30 anos & 70 \\
\hline Estado Civil & Solteiro & 53 \\
\hline Formação & Ensino Superior Incompleto & 32 \\
\hline Faixa salarial mensal & De R\$ 724,01 até R\$ 1.448,00 & 33 \\
\hline Carga horária diária & Entre 7h e 8h & 35 \\
\hline $\begin{array}{l}\text { Flexibilidade da carga horária } \\
\text { diária }\end{array}$ & $\begin{array}{l}\text { Depende, pois não há uma regra rígida. Às vezes } \\
\text { chego e saio cedo; às vezes é o contrário }\end{array}$ & \\
\hline
\end{tabular}




\begin{tabular}{|l|l|c|}
\hline Ambiente de trabalho do criativo & Na sede de uma empresa & 63 \\
\hline $\begin{array}{l}\text { Satisfação em relação à } \\
\text { remuneração e aos benefícios }\end{array}$ & $\begin{array}{l}\text { Não! Faço um trabalho superior a minha } \\
\text { remuneração e os benefícios são insuficientes }\end{array}$ & 27 \\
\hline $\begin{array}{l}\text { Investir em cursos superiores e/ou } \\
\text { livres }\end{array}$ & Grau de importância mais assinalado: “5” & 41 \\
\hline Assistir filmes e séries & Grau de importância mais assinalado: “4” & 48 \\
\hline $\begin{array}{l}\text { Navegar em sites buscando } \\
\text { referências }\end{array}$ & Grau de importância mais assinalado: “5” & 43 \\
\hline $\begin{array}{l}\text { Frequentar eventos ligados à área, } \\
\text { museus, exposições etc }\end{array}$ & Grau de importância mais assinalado: “5” & 33 \\
\hline $\begin{array}{l}\text { Praticar esportes e outras } \\
\text { atividades que ajudam a desopilar }\end{array}$ & Grau de importância mais assinalado: “4” & 33 \\
\hline Curtir o tempo ocioso & Grau de importância mais assinalado: “5” & \\
\hline
\end{tabular}

Fonte: Elaborado pelos autores

Ao fim do estudo, constata-se que o mesmo atingiu seus objetivos, contribuindo para uma maior compreensão do panorama criativo na cidade de Novo Hamburgo/RS. Destaca-se o fato de o mesmo ter ultrapassado a meta estabelecida para o número de respondentes da pesquisa que, inicialmente, previa 323 e, ao fim da coleta, atingiu a meta de 339 entrevistados, o que, de forma lídima, contribuiu, ainda mais, para a validação dos resultados.

Como projeção para futuros estudos, estabelece-se, inclusive, a continuação do trabalho, abordando questões relativas aos 3Ts teorizados por Florida (2014), observando aspectos relativos à tecnologia, tolerância e talento na localidade hamburguense. Tal extensão do conhecimento contribuirá, solidamente, para a captação de informações relevantes e oportunas, a fim de que se possam produzir documentos sólidos sobre a Indústria Criativa na cidade de Novo Hamburgo/RS.

\section{REFERÊNCIAS}

1. ASHEIM, Bjørn; HANSEN, Høgni Kalsø. Knowledge Bases, Talents, and Contexts: On the Usefulness of the Creative Class Approach in Sweden. Economic Geography, n. 85, v. 4, 2009, p. 425-442.

2. BARTH, Mauricio; MUSSKOPF, M. M. Publicidade na terceira idade: o caso Havaianas. Temática, João Pessoa, v. 8, p. 1-7, 2012.

3. BEATO, Marina. A obra de arte na interface do processo criativo e do processo tecnológico. Mestrado em Ensino de Educação Visual e Tecnológica no Ensino Básico. Setúbal, 2012.

4. BENDASSOLLI, Pedro F. Indústrias criativas: definição, limites e possibilidades. RAE, São Paulo, v. 49, n.1, jan./mar. 2009.

5. CHAPAIN, Caroline; COMUNIAN, Roberta. Dynamics and differences across creative industries in the UK: exploring the case of Birmingham. Redige, v. 2, n. 02, Aug. 2011.

6. DEHEINZELIN, Lala. Economia Criativa e métodos para dar uma mão ao futuro. Redige, v. 2, n. 02, ago. 2011.

7. FELÍCIO, Alexandre. Pessoas criativas são mais felizes e ganham mais. São Paulo: Audiolivro, 2014. 
8. FIRJAN. Mapeamento da Industria Criativa no Brasil. Disponível em: <http://www.firjan.org.br/economiacriativa/pages/default.aspx>. Acesso em: 01 mai. 2014.

9. FLORIDA, Richard. Rise of the Creative Class - Revisited. EUA: Basic Books, 2014.

10. HOWKINS, John. The Creativy Economy: How People make Money from Ideas. EUA: Penguin Books, 2002.

11. JUNCO, Reynol. Inequalities in Facebook use. Computers in Human Behavior, 2013, v. 29(6), p.2328-2336.

12. NICOLACI-DA-COSTA, Ana Maria. O talento jovem, a internet e o mercado de trabalho da "economia criativa". Psicologia \& Sociedade, v. 23 (3), p. 554-563, 2011.

13. PRODANOV, Cleber Cristiano; FREITAS, Ernani Cesar de. Metodologia do trabalho científico: métodos e técnicas da pesquisa e do trabalho acadêmico. 2. ed. Novo Hamburgo, RS: Feevale, 2013.

14. REIS, Ana Carla Fonseca. Cidades Criativas - da Teoria À Prática. São Paulo: Sesi, 2012.

15. RYAN, Tracii; XENOS, Sophia. Who uses Facebook? An investigation into the relationship between the Big Five, shyness, narcissism, loneliness, and Facebook usage. Computers in Human Behavior, 2011, v. 27(5), p.1658-1664.

16. SCHEMES, Claudia; PRODANOV, Cleber Cristiano; THÖN, Ida Helena; MARTINS, Rodrigo Perla. Memória do setor coureiro-calçadista: pioneiros e empreendedores do Vale do Rio dos Sinos. Novo Hamburgo, RS: Feevale, 2005.

17. SIMONTON, Dean Keith. Creativity: Cognitive, Personal, Developmental and Social Aspects. American Psychologist, v. 55, n. 1, p. 151-158, 2000.

18. VALIATI, Leandro. Indústria criativa no Rio Grande do Sul: síntese teórica e evidências empíricas. Porto Alegre: FEE, 2013. 


\section{APÊNDICE A - QUESTIONÁRIO}

\section{A VIDA DOS CRIATIVOS DE NOVO HAMBURGO/RS}

Inicialmente, pedimos que, abaixo, responda as perguntas-filtro. Caso não se enquadre em nenhuma das opções, não é necessário continuar.

Aproveite este tempo livre e tome um bom café

$=$ )

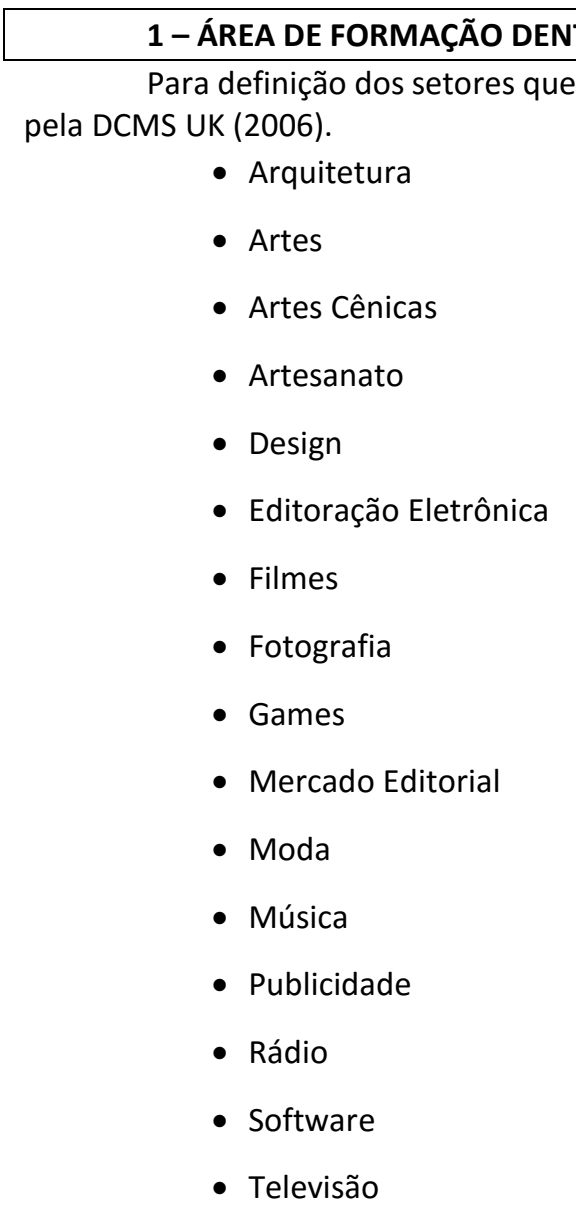

2 - DADOS DEMOGRÁFICOS

Sexo

- Masculino

- Feminino

Idade

- Menos de 20 anos

- $\quad$ Entre 21 e 30 anos

- $\quad$ Entre 31 e 40 anos

- $\quad$ Entre 41 e 50 anos

- Acima de 51 anos 
Estado Civil

- Solteiro(a)

- Casado(a)/União Estável

- Divorciado(a)/Separado(a)

- $\quad$ Viúvo(a)

\section{Formação}

- Ens. Fund. incomp.

- Ens. Fund. compl.

- Ensino Méd. incomp.

- Ensino Méd. compl.

- Ensino Superior incomp.

- Ensino Superior compl.

- Pós-Graduação incomp

- Pós-Graduação compl.

\section{Faixa salarial}

- $\quad$ Até $\mathrm{R} \$ 724,00$

- $\quad$ De $\mathrm{R} \$ 724,01$ até $\mathrm{R} \$ 1.448,00$

- De $\mathrm{R} \$ 1.448,01$ até $\mathrm{R} \$ 2.896,00$

- $\quad$ De $R \$ 2.896,01$ até $R \$ 5.792,00$

- $\quad$ De $R \$ 5.792,01$ até $\mathrm{R} \$ 11.584,00$

- $\quad$ De $\mathrm{R} \$ 11.584,01$ até $\mathrm{R} \$ 23.168,00$

- $\quad$ Acima de $\mathrm{R} \$ 23.168,00$

- Não quero informar

\section{3 - 0 AMBIENTE DO PROFISSIONAL CRIATIVO}

Qual sua carga horária diária?

(Caso você não possua uma rotina, estabeleça, com base em uma média diária, sua carga horária)

- Menos de 7 horas

- $\quad$ Entre $7 \mathrm{~h}$ e $8 \mathrm{~h}$

- $\quad$ Entre 8h01min e 9h

- Entre 9h01min e 10h

- $\quad$ Mais de 10h01min 
Dentro de sua carga horária, você tem algum tipo de flexibilidade?

- Sim! Posso chegar mais tarde, mas, em compensação, preciso ficar mais tempo após o horário

- Não! Devo cumprir exatamente o horário estabelecido em contrato

- Depende, pois não há uma regra rígida. Às vezes chego e saio cedo; às vezes é o contrário

- Como sou meu próprio "patrão", faço meus horários

Em que ambiente você trabalha?

- Na sede de uma empresa

- Em seu home office

- Em um ambiente de co-working

- Em locais públicos (livrarias, cafés, etc...)

- Outros

Considerando suas atividades de trabalho e seu desempenho nas mesmas, você está satisfeito com a remuneração e os benefícios?

(entende-se benefícios como outros aspectos do trabalho que não são, necessariamente, ligados à área financeira, como bom ambiente, desenvolvimento criativo, possibilidade de aprimoramento profissional etc)

- $\quad \operatorname{Sim}$ ! Estou satisfeito com a remuneração e os benefícios

- Em parte! A remuneração é atrativa, porém, os benefícios deixam a desejar

- Depende! A remuneração não é boa, contudo, os benefícios oferecidos são interessantes

- Não! Faço um trabalho superior a minha remuneração e os benefícios são insuficientes

Dentre as atividades abaixo, qual o grau de importância que você dá a cada uma delas em relação à contribuição das mesmas para seu desenvolvimento enquanto profissional criativo.

(entende-se 1 como "pouco importante" e 5 como "importância vital")

\begin{tabular}{|c|c|c|c|c|c|c|}
\hline & 1 & 2 & 3 & 4 & 5 & $\begin{array}{c}\text { Não } \\
\text { sei/Não se } \\
\text { aplica } \\
\end{array}$ \\
\hline $\begin{array}{l}\text { Investir em cursos } \\
\text { superiores e/ou livres }\end{array}$ & $\bullet$ & $\bullet$ & $\bullet$ & $\bullet$ & $\bullet$ & $\bullet$ \\
\hline Assistir filmes e séries & $\bullet$ & $\bullet$ & $\bullet$ & $\bullet$ & $\bullet$ & • \\
\hline $\begin{array}{l}\text { Navegar em sites buscando } \\
\text { referências } \\
\text { Frequentar eventos ligados }\end{array}$ & $\bullet$ & $\bullet$ & $\bullet$ & $\bullet$ & $\bullet$ & $\bullet$ \\
\hline $\begin{array}{l}\text { à área, museus, exposições } \\
\text { etc }\end{array}$ & $\bullet$ & $\bullet$ & $\bullet$ & $\bullet$ & $\bullet$ & - \\
\hline $\begin{array}{l}\text { Praticar esportes e outras } \\
\text { atividades que ajudam a } \\
\text { desopilar }\end{array}$ & $\bullet$ & $\bullet$ & $\bullet$ & $\bullet$ & • & • \\
\hline Curtir o tempo ocioso & $\bullet$ & $\bullet$ & $\bullet$ & $\bullet$ & $\bullet$ & $\bullet$ \\
\hline
\end{tabular}

